\title{
AC 2009-196: CREATORS, PARTICIPANTS, AND OBSERVERS: CLICKERS, BLOGS, AND PODCASTING OFFER STUDENTS MORE THAN JUST A SEAT IN THE CLASSROOM
}

\section{Kathy Schmidt, University of Texas, Austin}

KATHY J. SCHMIDT is the Director of the Faculty Innovation Center for the Cockrell School of Engineering at the University of Texas at Austin. In this position, she promotes the School's commitment to finding ways to enrich teaching and learning. She works in all aspects of education including design and development, faculty training, learner support, and evaluation. Contact k.schmidt@mail.utexas.edu

\section{Juan Garcia, University of Texas, Austin}

JUAN GARCIA is a Video Producer for the Faculty Innovation Center with specialties in new media, social networks and mobile content distribution. He has spoken about new media trends for various organizations, including Apple, the Dallas Video Festival, Leadership Austin, and the World E-Democracy Forum in Paris, France. Along with his work, Juan sits on the board of directors for several educational media arts organizations and frequently supports organizations in the development of youth-generated media programs.

\section{Michael Webber, University of Texas, Austin}

MICHAEL WEBBER is the Associate Director of the Center for International Energy and Environmental Policy in the Jackson School of Geosciences, Fellow of the Strauss Center for International Security and Law at the LBJ School of Public Affairs, and Assistant Professor of Mechanical Engineering at the University of Texas at Austin, where he trains a new generation of energy leaders through research and education. 


\title{
Creators, Participants, and Observers: \\ Podcasting, Blogs, and Clickers Offers Students More than Just a Seat in the Classroom
}

\begin{abstract}
Today's students are often passive receivers of media-based instructional materials and rarely have the opportunity to actively participate in their creation. One up-and-coming technology that is compatible with self-directed education is a podcast, which is an audio or video file distributed to an appropriate media player over the Internet. Our students in a multidisciplinary mechanical engineering class were able to go beyond being a consumer and instead became creators of podcasts and active participants through blogs and a classroom response system (clickers). With the use of new technologies and software tools, students were given the opportunity to create and post podcasts of their own research. Because the assignment was optional (students had a choice of writing a paper or creating a podcast on their original research) not all of the students created podcasts. Both types of completed projects (papers and podcasts) were uploaded to the class blog. In class students were actively involved by responding to instructor questions via clickers. In addition, both groups of students were given pre- and post-surveys to ascertain and compare pre-project expectations with post-project assessments of their time commitments, skills needed, level of enjoyment, and perceptions on their learning.
\end{abstract}

\section{Introduction}

Educating and engaging today's students who are fluid with the latest in technology often involves the use of technological teaching tools. Last spring when a new mechanical energy course was offered, the course was designed using instructional tools to not only distribute information but to actively involve students in the learning process. The technologies include iclickers that consists of remote controls for each student and a receiver that records student answers to questions posed by the instructor; blogs (a contraction of the term Web log) contains student entries combining text, images, links, etc. or multimedia lectures enhanced with graphics and motion video; and podcasting which can be defined as "a digital recording of a radio broadcast or similar program, made available on the Internet for downloading to a personal audio player." 1

In this course, the technology was used "beyond the lectures" in that students were actively developing blogs and if they selected to, they created a podcast. In higher education, most existing uses of podcasting result in the delivery of content for a lecture. Yet podcasting can go beyond delivery and engage students in the learning process. ${ }^{2}$ Our goal in this course was to enhance learning and to use technology as a means to do so. We studied not only the efficacy of these technologies, but whether or not students viewed these tools positively. Students responded to pre- and post-surveys that questioned their use and preference for these technologies. This paper will provide a discussion of the tools used, a comparison of these results, and will conclude with recommendations for integrating such technologies into your classes. 


\section{Background}

It is not the media or technology that causes learning to improve for it is the instructional strategy and content that influence learning. Many studies have found that there is "no significant difference" when comparing mediated instruction to traditional instruction and frankly pursuing that line of research is unnecessary. We should not change our teaching styles to accommodate the technology; the technology is a tool to help achieve instructional goals. With the course objectives as a guide, you can select which technology tools can help promote student learning and engagement.

Technology can be used to promote interaction in classroom. Through the use of personal response devices (or "clickers"), students are able to use a hand-held device to press a button and respond to a question. Students can then see the class distribution of answers on a screen and participate in discussing the thinking that leads to the correct answer. Instructors need to carefully craft questions so that students are not merely responding to low level questions in a rote-learning environment. It is generally reported that students are favorable about the use of clickers while empirical evidence of their effectiveness is still limited. In a quantitative study by Mayer et al., students who used clickers scored significantly higher. ${ }^{3}$ These results are consistent with the generative theory of learning, which predicts students in the clicker group are more cognitively engaged during learning. In earlier qualitative studies, clickers have been found to stimulate class discussion and to help the professor ask a range of questions, from checking basic understanding to more in-depth reasoning. ${ }^{4}$ Others are looking at particular aspects of using personal response devices such as whether or not gender differences come into play. In one study, a higher percentage of females were actively participating in class when they had clickers. This participation, however, only resulted in a gain of points over the non-active females. ${ }^{5}$ The research to date suggests the pedagogical effectiveness of clickers is dependent upon how an instructor uses them.

Outside of class students, blogs (web log) are used to promote student interactions, reflection and to facilitate between class communications. According to Winer, "a Web log is a hierarchy of text, images, media objects, and data, arranged chronologically, that can be viewed in an HTML browser." ${ }^{6}$ Blogs are easy to construct for all that is needed is a Web browser and an Internet publishing service. Given their ease of use and their proliferation, they are used frequently in all levels of education. The pedagogical paradigm that supports the use of blogs in educational settings is Vygotsky's educational theory that states children learn from social interaction. ${ }^{7}$ College students, however, also bring lived experiences to their learning. The use of a blog that provided as images, multimedia, audio, and text is a good way for students to engage in written communication. Students are better able to communicate and discuss ideas when using computer mediated communication environments. ${ }^{8}$ One study done in an online health education class found that blogging can enhance peer interaction, allow for synthesis of course content, and help sustain student engagement. ${ }^{9}$

Podcasting, an amalgamation of the words "iPod" and "broadcasting," first became culturally popular in 2004. It was in late 2005 when Apple, Inc. introduced new consumer software tools that the podcast adoption and creation rate increased within higher education institutions. Initially, podcasting was only available as audio files, and distributed in the MPEG-1, Audio Layer 3 digital encoding format, or what is more commonly known as "MP3" files. Today, 
podcasts have expanded capabilities, and can include many file types, including audio, video, synch slide presentations or even PDF document files for distribution over the Internet. What makes podcasting possible, and stand apart from streaming media, is found in the media type's distribution method. Using what is known as "RSS feeds" podcasts can be "pushed" via a media server and "pulled" by an end user audience through the use of media aggregators, such as iTunes. These aggregators gather data from the RSS feed, or "Really Simple Syndication" file types, though the use of Extensible Markup Language files (XML) and communicate directly with the media servers. Once a new media file is made available, the XML file refreshes the RSS feed and the new media is automatically delivered to the end user's computer system or personal portable media device (PMD). Following the download process to the computer or PMD, files can then be played back, or opened, for listening or viewing. Due to the high technology codecs used to encode, or compress, these files, podcasts are typically of better audio and/or video quality than streaming media, but likewise, do not serve the same function as streaming media which is traditionally the premiere choice for live events, whereas podcasting is of greater use for archived or episodic media files.

Evidence for the educational effectiveness of podcasts is growing and there is a need for further studies to reveal the pedagogical potential of podcasting. The most prevalent use of podcasting in higher education is for delivering instructional content. A preliminary study of podcasting in engineering education by Berger used podcasting for video problem solutions, roundtable discussions, and exam reviews. Students strongly favored the podcasting with weaker students perceiving more benefits to podcasting. ${ }^{10}$ In a study of undergraduates that used podcasts to review material prior to the final examination, statistical analysis indicates that students believe that podcasts are more effective revision tools than their textbooks and they are more efficient than their own notes in helping them to learn. ${ }^{11}$ Looking beyond the research on podcasting as a "technology driven pedagogy" yields few examples of podcasting usage empowering students and encouraging active learning. ${ }^{2}$ We voice what we've heard said by others by saying that podcasting's potential is in its ability for student knowledge creation and sharing of content.

\section{Course Description}

Energy, technology and policy is an upper-division undergraduate course open to students in engineering and graduate students in engineering, energy \& earth resources, business, or public affairs. The course is an overview of energy technologies, fuels, environmental impacts and public policies. Topics are interdisciplinary and include an introduction to quantitative concepts in energy, including the differences among fuels and energy technologies, energy policy levers, and the societal aspects of energy, such as culture, economics, war, and international affairs. This course covers brief snippets of energy history, uses real-world examples, looks forward into the future, and benefits from guest speakers. Emphasis is given to the role of Texas as a leader (and laggard) in U.S. and world energy policy.

The course is interactive and lecture-oriented around current events related to energy. Class attendance and participation is required. Students are required to blog three times during the semester on energy topics, comment regularly on other student's blog entries, create an original podcast or write a paper on a topic that combines energy policy and technologies, conduct an individual research project, and take a final exam that covers the lectures and reading assignments. 


\section{Using Technology to Support Learning in the Course}

The instructional technologies integrated into this course each support a pedagogical purpose. The clickers get students involved and promote active learning. Clickers were used regularly during the lectures to gauge student understanding and to promote interactions. Although it was not a stated purpose of the clickers, it was hoped that their use prompted students to think about their level of understanding and to ask more questions.

Use of blogs in the course encouraged peer-to-peer interactions and the social construction of knowledge. At least three times during the semester, each student was required to post a blog. They were also to respond to classmate's blogs, but the number of times they were to do so was not specified. Blogger, a blogging tool provide by Goggle, was used. It is not a password word protected site, however, and is available to anyone with Internet access.

Students were given the option of creating a podcast in lieu of writing a final research paper, and were strongly encouraged to use this new media format to produce short PSAs that focused on various energy issues. The School of Engineering's Faculty Innovation Center (FIC) commissioned an Apple iMac computer on which students could edit media (audio or video) with or without supervision from FIC staff. Likewise, the University of Texas Apple Student Campus Representatives played a key role during this project by helping the FIC demonstrate audio and video editing techniques during student group training sessions, and were also available for one-on-one sessions throughout the production process. Consumer software applications iTunes, iPhoto, iMovie, and GarageBand were prevalently used, with additional utilization of Keynote, PowerPoint, and Windows Movie Maker. This project was the first largescale initiative of its kind at the University of Texas in which students were the creators of course podcasts, and received a grade for these podcasts.

\section{Student Insights on Technology Usage}

While the technology used in this class seemed well-received by the students, we wanted to find about some specifics from the students. To assess the benefits, drawbacks and impacts of these technologies in this class, we gave the students a short survey at the beginning and end of the semester. We not only want to find out their perceptions, but we also wanted to gauge their familiarity with the class instructional technologies. At the end of the semester, we surveyed students to gather data on their creation and using of podcasts and their views on the pedagogical benefits of podcasting and other class technologies. Table 1 lists the demographic data on the students enrolled in Energy, Technology and Policy. A total of 59 students responded to the first survey and most of them are engineering students along with students from business, public affairs, and energy and earth resources.

Table 1 Demographic information describing students in $M E$

\begin{tabular}{ll}
\hline Sex & \\
Male & $40(68 \%)$ \\
Female & $19(32 \%)$ \\
\hline Educational level & \\
Junior & $3(5 \%)$ \\
Senior & $13(23 \%)$
\end{tabular}


Given that this generation of students is known as digital natives, we asked on the first survey about their usage of technology (clicker questions were only asked in the post-survey).

Students entered this class with positive ideas about blogging with $80 \%$ responding that blogging will enhance their learning. Although another $8 \%$ liked blogging, but questioned how they will help them to learn. Students, however, overwhelming think that blogs are useful (80\%), but that didn't necessarily translate into thinking a blog is a useful forum for technical content. Still, a majority of $62 \%$ thought they were with useful for technical content with slightly more than a quarter of the students thinking the opposite.

Owning an iPod is common for $82 \%$ do although only $65 \%$ had ever listed to a podcast. Surprisingly $5 \%$ don't know about podcasts, however, two of the students have created their own podcasts. So far only a quarter of them have been exposed to any educational podcasts yet when asked to identify benefits to educational podcasts, they found that many including: convenience, reduced dependency on physical material, enhanced support for individual learning preferences, the linking of in-class learning with outside-the class learning, and new opportunities to learn from classmates. The assumption, however, that podcast are a good medium to learn technical content was not a universal notion: only 54\% thought it would be while another $41 \%$ were uncertain. Only 5\% thought it was not appropriate for technical content. When asked how much time they anticipated spending listening to a podcast, their responses reflect that context does matter and one quarter of them think 6 to 10 minutes is adequate (see Figure 1).

Figure 1 Amount of time students predict they will spend with a podcast

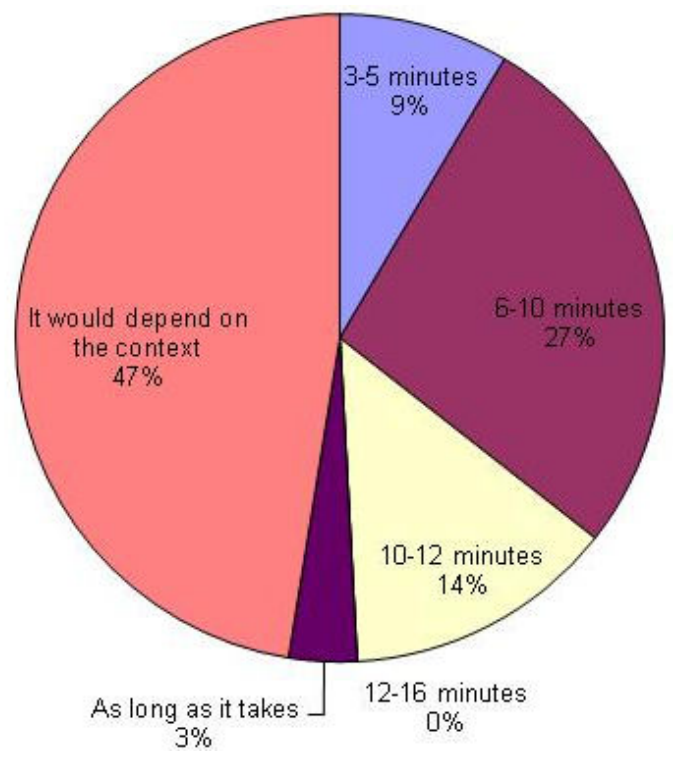

Students were asked how often they review educational podcasts. Given that many students, $71 \%$, have not had podcast available it is hard to get a picture of usage. When they missed class, 9\% said they reviewed podcasts. In this class, however, podcasts aren't the lectures, but rather, they are student produced. They were asked if they found it helpful to review other classmate's 
papers and half of them said they did. Although close to half (44\%) sometimes found it helpful. When asked if they will look at classmate's podcasts, 55\% said they would along with $32 \%$ who don't know and $13 \%$ who said no.

At the end of the course, students were given another survey. A majority of the students (56\%) found the clickers helpful, but a large percentage (39\%) found them neither helpful nor distracting. Only $5 \%$ found them distracting. The students are comfortable using the clickers as illustrated on Figure 2 and $43 \%$ found that using clickers increased their class participation. A majority (54\%) found that the clickers made no difference in their participation. We anticipated that students would be more responsive due to the use of clickers and in a future study we can gather data on how frequently students participate without a clicker as well as with a clicker. We would then need to see if participation in class is correlated with learning. A quarter of the students indicated they would like to see more use of the clickers while $64 \%$ felt their use was currently adequate.

Figure 2 Comfort with using the clicker to respond to questions

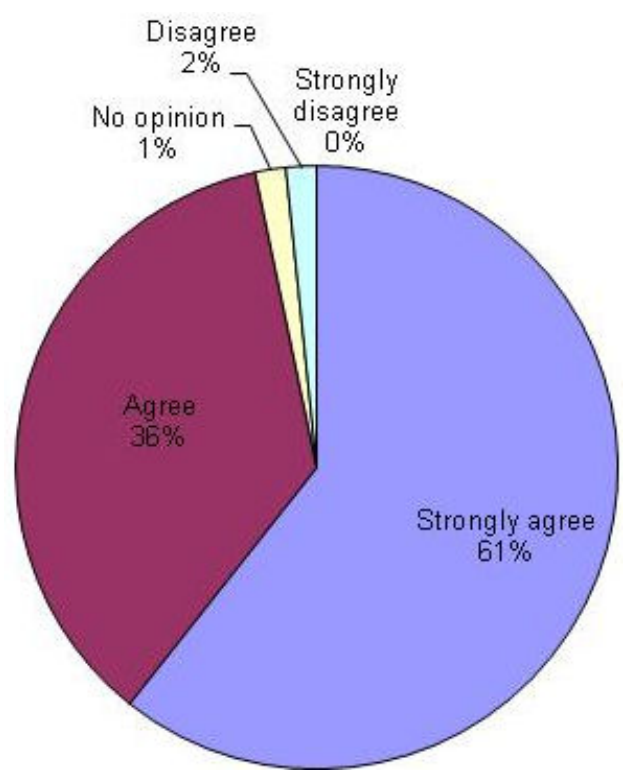

When students began the class, they overwhelmingly (80\%) thought blogging would enhance their learning. In the post-survey, $73 \%$ indicated positive ideas about blogging and $18 \%$ found blogs didn't enhance their learning. They did find, however, that blogs are useful sources of information (see Figure 3), but not necessarily reasonable forums for technical information. Coming into the class, $62 \%$ thought a blog was useful for technical content, but in the postsurvey, only $29 \%$ did. The majority of the students $(61 \%)$ were not sure if it was reasonable or not. While they were required to blog, little direction was provided as to how to respond. They might not have responded as technically as they could have and all blogs were text only. The use of rich media sources (i.e., video, audio, and visuals) would have helped them to present more in-depth responses. 
Figure 3 Blogs are useful sources of information

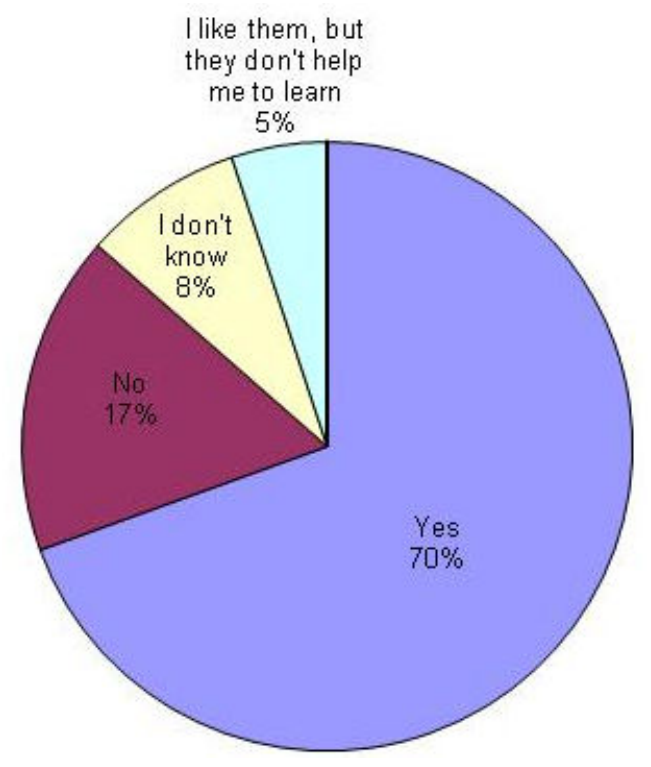

When class ended, fewer students had created podcasts than initially expected. When asked on the post-survey if they had made a podcast, only $24 \%$ had done so. Half of the class had opted out, but $21 \%$ had initially planned to do so and had changed their minds. Another 5\% wished they had created a podcast. Their perceptions of whether or not a podcast is a good medium to learn technical content did not vary substantially between the beginning and end of the semester. They did indicate, however, that they invested more time creating a podcast (average of 39 hours) over writing a paper (31 hours). Keep in mind that that is not a direct comparison for an individual student, but rather the average number of hours by all students. On the pre-survey 15 students stated that an educational benefit to podcasting is an increased interest in learning and on the post-survey that number went up to 25 . They found, however, that fewer connected podcasting with linking in-class learning with outside-of-class learning (32 pre-survey responses and 17 post-survey responses). Figure 4 illustrates that podcasting was a valuable experience, although close to $40 \%$ did not necessarily agree. This is an area for further exploration for over half $(54 \%)$ indicated they would like the option to create a podcast in other courses. A quarter of the students do not want this option with the other quarter uncertain. When asked why they didn't create a podcast, the responses were: nine were not interested; nineteen thought it would be too time consuming; nine thought it would be too difficult and; eighteen had other reasons. We will need further exploration on why that mean are hesitant for the surveys show that some students didn't feel like they lacked technical abilities. Eighteen suggested they could create a podcast without assistance. 
Figure 4 Value of podcasting experience

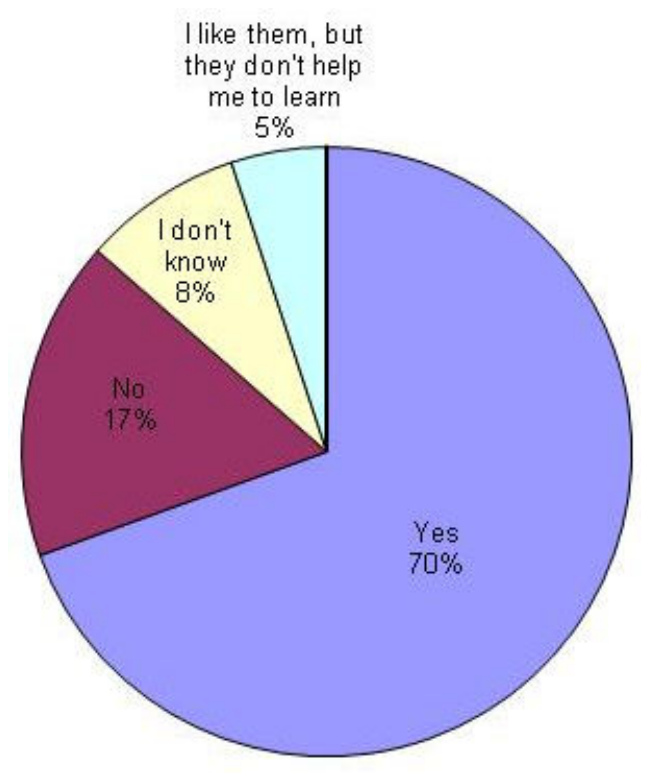

\section{Practical Suggestions}

Clickers have been available for more than ten years and are now fairly reliable. Before selecting a clicker review the different products on the market. Others at your university may already be using them and can make recommendations. If your students are required to purchase a clicker, you need to incorporate it into your class on a regular basis. They resent spending money on something that is seldom used. Take into account that you will need to allow time to create questions and that you should evaluate the questions after the students have responded to them (some may need to be eliminated or edited). Be thoughtful about how clickers can encourage interactions and participation so that you include other opportunities for the students to interact.

Just like with the clickers, you should look around before selecting a blogging tool. The more robust sites will allow for rich media sources to be included. Don't just assume that your students will respond appropriately. Provide a structure for the blogs so that students give adequate and timely responses. You should also state what role you will play in the blogging. If you are using a non-authenticated blogging tool, you need to consider student privacy issues and see what is allowable according to the Federal Right to Privacy Act (FERPA).

For those who wish to implement a similar podcasting program, it is necessary to first appropriate enough time in advance of the semester to experiment with tools and software that fit the needs of your program. The number of students enrolled, participating and time allowed for each student to work on a podcast all factor into how the projects will be created. Key points such as media file size, audio or video presentation length, encoding platform (Windows versus $\mathrm{Mac}$ ) and server hosting are important points to first consider. Podcasting, though appearing seamless in distribution, requires significant setup time. Once the previously stated factors have been determined, the next steps are to enlist an XML software program to generate an RSS feed specific to the podcast. This RSS feed will then need to be submitted to iTunes (or aggregator of 
choice) for future distribution. When student presentations are finished, their native files may not be "podcast ready," as students typically will not have access to the encoding software needed for this. Podcasts must be exported from software editing programs in a .M4V, M4A, or .MP3 format (video, enhanced and audio podcast file formats respectively). These files can then be uploaded to a chosen podcast folder on a media server, and then using the same XML and RSS generation software, the feed can be updated to reflect the new media files added to the server. Updating the RSS feed is instantaneous, and all end users subscribed to the podcast will receive the new files automatically the next time they launch iTunes (or their aggregator of choice).

In the case of the Energy, Technology and Policy (ETP) student podcast project, the professor was able to use the resources and staff in the School's faculty center. The FIC was able to provide significant assistance with technical matters and the development of the class project. Working closely with the professor, the FIC was not only able to outline an entire program curriculum, but help produce this project from start to finish with in-house resources. Partnerships in this program also played an important role. During the class group training session, several University of Texas student representatives from Apple, Inc focused on presenting the full operational capabilities of the audio and video editing software platforms iMovie and GarageBand. Beyond the training sessions, both the Apple student representatives, as well as two part time student workers for the FIC, assisted Dr. Webber's students throughout the semester, and throughout the process, by answering technical questions and doing one on one podcast tutorials. These two key points helped free up the FIC staff, Dr. Webber, and the ETP course TA from these technical matters, but likewise, helped students feel as if they were receiving tips from peers. The ultimate technology goal on this project was to make said technology as transparent as possible for participating students, so that full focus was on the content of the podcast, and not the technology behind the podcast. This in effect allowed students to focus more clearly on their research topics, while encouraging creativity, and without requiring prior technical podcasting knowledge.

\section{Conclusions}

The use of technology can enrich your classroom as long as you first and foremost think about what pedagogical purpose the technology serves. Given the range of instructional tools available, you can integrate multiple tools into your instruction. Each of the tools introduced into this course were able to support different pedagogical purposes. The clickers result in active learning and provide students with necessary feedback during class time. The blogs promote social learning and offer an ongoing forum for discussion. Podcasts, often used to record lectures, were instead used as "knowledge creators" by a subset of students in this class. In the next iteration of this class, all students will be required to create a podcast. Based on this initial offering of this class, we will continue to use all of these tools and to gather ongoing feedback on their usefulness from the students. 


\section{References}

1. Merriam Webster Online. http://www.merriam-webster.com/ Accessed January 14, 2009.

2. Lee, M.J., McLoughlin, C., \& Chan, A. (2008). Talk the talk: Learner-generated podcasts as catalysts for knowledge creation. British Journal of Educational Technology, v39 (3), pp. 501-521.

3. Mayer, R.E., et al. (2009). Clickers in College Classrooms: Fostering Learning with Questioning Methods in Large Lecture Classes. Contemporary Educational Psychology, v34, (1), pp. 51-57.

4. Siegel, J., Schmidt, K.J., \& Cone, J. (2004). INTICE: Interactive technology to improve the classroom experience. Proceedings of the ASEE Annual Conference and Exposition, Salt Lake City, UT.

5. Reay, N. W., Li, Pengfei, \& Bao, Lei. (2008). Testing a new voting machine methodology. American Journal of Physics, 72(2), 171-178.

6. Winer D. (2003). What makes a weblog a weblog? [Weblogs at Harvard Law Web site] http://blogs.law.harvard.edu/whatMakesAWeblogAWeblog\#vignetteAndWikis Accessed January 14, 2009.

7. Vygotskoy, L.S. (1978). Mind in Society: The Development of Higher Psychological Processes. In: Cole M, John-Steiner V, Scribner S, Souberman E, trans-eds. Cambridge, MA: Harvard University Press.

8. Ocker, R.J. \& Yaverbaum, G.J. (2001). Collaborative learning environments: Exploring student attitudes and satisfaction in face-to-face and asynchronous computer conferencing settings, Journal of Interactive Learning Research, 12, pp. 427-449.

9. Oomen-Early, J., \& Sloane, B. (2007). Entering the Blogosphere: Blogs as Teaching and Learning Tools in Health Education, International Electronic Journal of Health Education, v10, pp. 186-196.

10. Berger, E. (2007). Podcasting in engineering education: A preliminary study of content, student attitudes, and impact. Journal of Online Education, v4 (1).

11. Evans, C. (2008). The effectiveness of m-learning in the form of podcast revision lectures in higher education. Computers \& Education, v50 (2), pp. 491-498. 